\title{
TRANSIENT CORTICAL BLINDNESS IN A 15 YEAR OLD BOY: A CASE REPORT
}

Lokesh Kulshrestha ${ }^{1}$

\section{HOW TO CITE THIS ARTICLE:}

Lokesh Kulshrestha. "Transient Cortical Blindness in a 15 Year Old Boy: A Case Report". Journal of Evolution of Medical and Dental Sciences 2014; Vol. 3, Issue 15, April 14; Page: 3895-3897,

DOI: $10.14260 /$ jemds/2014/2373

\begin{abstract}
Vision loss after non-ophthalmic surgery is a rare complication. A fifteen year old boy presented with acute abdomen in low general condition with mild hypotension and moderate dehydration. He was diagnosed as a case of intussception. He was resuccitated and exploratory laparotomy was done. Per-operative period was uneventful. Next day, patient complainted of vision loss. After full clinical ophthalmological exam and investigations, the diagnosis was made of cortical blindness due to infarction of occipital lobe. Vision loss recovered later. The cortical blindness was due to hypoperfusion secondary to hypotension. This complication commonly occurs after cardiac surgery or spinal surgery where usually low blood pressure is maintained during surgery. But it can also occur even after exploratory laparotomy. In conclusion, with the reported visual loss in this patient, surgeons should consider the possibility of vision loss after surgery.
\end{abstract}

KEYWORDS: Postsurgical cortical blindness; Hypotension; Exploratory laparotomy; Intussception

INTRODUCTION: Transient cortical blindness is a rare complication after non-ophthalmic surgery. This complication commonly occurs after cardiac surgery or spinal surgery, but it can also occur even after exploratory laparotomy as described in this case report.

CASE REPORT: A 15 year old boy was admitted in the surgical unit of the hospital with diagnosis of acute abdomen. On admission he was moderately dehydrated, his BP was 83/50 mm of $\mathrm{Hg}$, pulse rate was $135 / \mathrm{mt}$, low in volume but regular, respiratory rate was $24 / \mathrm{mt}$. Systemic examination was within normal limit. He had no remarkable past history.

Ultrasound of abdomen revealed intussusception of small intestine. His routine laboratory investigations were within normal limit except $\mathrm{Hb}$ level of $9 \mathrm{gm} / \mathrm{dl}$. For the management of acute abdomen, after putting central venous cannulation and fluid resuscitation, he was shifted to operation room.

In the theatre, his BP was $107 / 75 \mathrm{~mm}$ of $\mathrm{Hg}$, heart rate $112 / \mathrm{mt} \& \mathrm{SpO} 2$ was $99 \%$ on air. An exploratory laparotomy was done under general anesthesia and a surgical procedure of one and half hrs. duration was performed. Intraoperatively there was one episode of hypotension (BP 84/49 mm hg) and was managed by IV fluids only.

The total duration of hypotension was $8 \mathrm{mts}$ only. Estimated blood loss during operation was $250 \mathrm{ml}$. After reversal of anesthesia patient was transferred to PAC Unit with stable vitals. On 1st postoperative day, the attending nurse noted confusion in the patient's behavior and on interrogation; he complained of that he was unable to see anything.

Ophthalmologist consultation was sought which showed normal sized, normally reacting pupils and normal PL/PR \& no restriction of eyeball movements. Fundus examination was also within 
normal limit. Neurological exam was normal. An urgent MRI of brain was obtained which revealed small occipital infarct in the form of hypodense area.

Other investigations ordered were coagulation studies, chest X-ray, ECHO, ECG and all were normal. He was diagnosed as a case of cortical blindness. He was treated conservatively. Vision gradually started improving after 5 days. Patient was discharged on the 7 th postoperative day without any remarks.

DISCUSSION: Cortical blindness is defined as vision loss in a normal appearing eye due to damage to the occipital cortex. Cortical blindness is the resultant of oxygen deprivation to the occipital lobe.

Cortical blindness may also be transient in certain instances. ${ }^{1}$ Mechanism responsible for the transient blindness is unknown. It may be the resultant of transient hypoxia and cerebral dysfunction.

Recovery may be due to the resolution of the inflammation and edema around the lesion and re-activation of the partially damaged perilesional tissue. ${ }^{2}$

Transient cortical blindness in adults with identifiable cause is frequently encountered but less common in children.

In children, common causes of transient cortical blindness are the sequelae of some drug (like contrast media) administration and head trauma to the occipital lobe and loss of blood flow to the occipital cortex.

Post-operative vision loss after non-ophthalmic surgery is a rare event with the incidence ranging between $0.1 \%$ and $1 \%$ of cases. ${ }^{3}$ Majority incidences reported in following cardiac bypass surgery ${ }^{4}$ and spine surgery ${ }^{5}$. Visual loss after surgery is caused primarily due to emboli, severe low blood pressure, acute anemia, hypoxia or a combination of these factors. ${ }^{1,6}$

Cortical blindness may be a resultant of severe and prolonged hypotension or embolism/thrombosis from heart, aortic arch or carotid vertebra-basilar artery during or postsurgery as described by Kamata J et al ${ }^{7}$. In most cases complete recovery occurs. In the present case, cortical blindness is reported after exploratory laparotomy.

William et al. 6 examined 92 patients who experienced visual loss after undergoing cardiac and noncardiac surgery. Twenty seven cases were cortical blindness, of which 22 cases occurred after cardiac surgery (81\%).

Aldrich et al. ${ }^{1}$ reported a retrospective study of 25 patients, where the causes of cortical blindness were natural ischemic stroke in 8 patients (32\%), cardiac surgery in 5 patients (20\%), cerebral angiography in 3 patients (12\%), non-surgery in 4 patients (16\%), seizure in 2 patients (8\%), and other factors, such as damage to the head and peritoneal dialysis, in 3 patients (12\%). There were also cases of temporary cortical blindness reported after post cardiac surgery angiography. ${ }^{6}$

Rodriguez and Belway ${ }^{8}$ stated that in the cases of pediatric cardiac surgery, the likelihood of microembolization due to the long extracorporeal circulation time produced by hypotension present in initial phase of management might be the cause of cortical blindness.

The most likely cause in this patient could be due to hypoperfusion secondary to hypovolemia \& hypotension. Review of MRI revealed infarction/ischemia of both occipital lobes. Embolic event seems unlikely as the whole course of basilar artery was normal \& there was no evidence of cardiac disease on history or ECHO studies. 
In conclusion, with the reported visual loss in this patient, surgeons should consider the possibility of visual loss after the surgery as a complication. Considerable effort should be made to prevent hypoperfusion. Any complain with vision loss should be observed carefully and managed immediately.

\section{REFERENCES:}

1. Aldrich MS, Alessi AG, Beck RW, Gilman S. Cortical blindness: etiology, diagnosis, and prognosis. Ann Neurol 1987; 21: 149-58.

2. Poggel DA et al. Unusual spontaneous and training induced visual field recovery in a patient with gun- shot lesion. J Neurol Neurosurg Psychiatry 2001; 70: 236-9.

3. Shahian DM, Speert PK. Symptomatic visual deficits after open heart operations. Ann Thorac Surg 1989; 48: 275-9.

4. Bagheri J, Mandegar MH, Sarzaeem MR, Chitsaz S. Transient bilateral cortical visual loss after coronary artery bypass grafting in a normotensive risk-free patient. Heart Surg Forum 2008; 11: E248-51.

5. Nathan ST, Jain V, Lykissas MG, Crawford AH, West CE. Transient cortical blindness as a complication of posterior spinal surgery in a pediatric patient. J Pediatr Orthop B. 2013 Feb 11;

6. Williams EL, Hart WM Jr, Tempelhoff R. Postoperative ischemic optic neuropathy. Anesth Analg 1995; 80: 1018-29.

7. Kamata J, Fukami K, Yoshida H, Mizunuma Y, Moriai N, Takino T, et al. Transient cortical blindness following bypass graft angiography. A case report. Angiology 1995; 46: 937-46.

8. Rodriguez RA, Belway D. Comparison of two different extracorporeal circuits on cerebral embolization during cardiopulmonary bypass in children. Perfusion 2006; 21: 247-53.

\section{AUTHORS:}

1. Lokesh Kulshrestha

\section{PARTICULARS OF CONTRIBUTORS:}

1. Associate Professor, Department of Surgery, S. N. Medical College, Agra.

\section{NAME ADDRESS EMAIL ID OF THE} CORRESPONDING AUTHOR:

Dr. Lokesh Kulshrestha, \#23, Suresh Nagar, Agra - 282005, India.

E-mail: lokesh@doctor.com

Date of Submission: 27/02/2014. Date of Peer Review: 28/02/2014. Date of Acceptance: 22/03/2014. Date of Publishing: 08/04/2014. 